\title{
Erratum zu: Antiandrogene Behandlung von Menschen mit Intelligenzminderung in der ambulanten Nachsorge
}

\author{
Tatjana Voß ${ }^{1}$ - Rebecca Reichel' - Daniela Calvano' \\ Online publiziert: 23. August 2021 \\ (c) Der/die Autor(en) 2021
}

\section{Erratum zu:}

\section{Forens Psychiatr Psychol Kriminol 2020}

https://doi.org/10.1007/s11757-020-00635-8

Der Artikel „Antiandrogene Behandlung von Menschen mit Intelligenzminderung in der ambulanten Nachsorge“" von Tatjana Voß, Rebecca Reichel und Daniela Calvano wurde ursprünglich „online first“ ohne „Open Access“ auf der Internetplattform des Verlags publiziert. Nach der Veröffentlichung in Bd. 15, Heft 1, S. 62-72 hatten sich die Autoren für eine „Open-Access“"-Veröffentlichung entschieden. Das Urheberrecht des Artikels wurde deshalb in (C) Der/die Autor(en) geändert. Dieser Artikel ist jetzt unter der Lizenz Creative Commons Namensnennung 4.0 International veröffentlicht, welche die Nutzung, Vervielfältigung, Bearbeitung, Verbreitung und Wiedergabe in jeglichem Medium und Format erlaubt, sofern Sie den/die ursprünglichen Autor(en) und die Quelle ordnungsgemäß nennen, einen Link zur Creative-Commons-Lizenz beifügen und angeben, ob Änderungen vorgenommen wurden.

Die in diesem Artikel enthaltenen Bilder und sonstiges Drittmaterial unterliegen ebenfalls der genannten Creative Commons Lizenz, sofern sich aus der Abbildungslegende nichts anderes ergibt. Sofern das betreffende Material nicht unter der genannten Creative Commons Lizenz steht und die betreffende Handlung nicht nach gesetzlichen Vorschriften erlaubt ist, ist für die oben aufgeführten Weiterverwendungen des Materials die Einwilligung des jeweiligen Rechteinhabers einzuholen. Weitere Details zur Li- zenz entnehmen Sie bitte der Lizenzinformation auf http:// creativecommons.org/licenses/by/4.0/deed.de.

Funding Open Access funding enabled and organized by Projekt DEAL.

Open Access Dieser Artikel wird unter der Creative Commons Namensnennung 4.0 International Lizenz veröffentlicht, welche die Nutzung, Vervielfältigung, Bearbeitung, Verbreitung und Wiedergabe in jeglichem Medium und Format erlaubt, sofern Sie den/die ursprünglichen Autor(en) und die Quelle ordnungsgemäß nennen, einen Link zur Creative Commons Lizenz beifügen und angeben, ob Änderungen vorgenommen wurden.

Die in diesem Artikel enthaltenen Bilder und sonstiges Drittmaterial unterliegen ebenfalls der genannten Creative Commons Lizenz, sofern sich aus der Abbildungslegende nichts anderes ergibt. Sofern das betreffende Material nicht unter der genannten Creative Commons Lizenz steht und die betreffende Handlung nicht nach gesetzlichen Vorschriften erlaubt ist, ist für die oben aufgeführten Weiterverwendungen des Materials die Einwilligung des jeweiligen Rechteinhabers einzuholen.

Weitere Details zur Lizenz entnehmen Sie bitte der Lizenzinformation auf http://creativecommons.org/licenses/by/4.0/deed.de.
Die Online-Version des Originalartikels ist unter https://doi.org/ 10.1007/s11757-020-00635-8 zu finden.

Dr. med. Tatjana Voß

tatjana.voss@charite.de

1 Institut für Forensische Psychiatrie,

Forensisch-Therapeutische Ambulanz, Charité -

Universitätsmedizin Berlin, Seidelstraße 38, 13507 Berlin,

Deutschland 